\title{
AS MARCAS DO GÓTICO NA NARRATIVA FANTÁSTICA DE SILVINA OCAMPO
}

\section{THE GOTHIC FEATURES IN SILVINA OCAMPO'S FANTASTIC NARRATIVE}

\author{
Rafael Eisinger Guimarães ${ }^{1}$
}

\begin{abstract}
RESUMO: A escritora argentina Silvina Ocampo desenvolveu uma produção literária instigante e consistente, com especial destaque para seus sete volumes de contos, nos quais se observa a forte presença do fantástico. No entanto, além dessas características, alguns traços da narrativa gótica podem ser vistos ao longo de sua obra. Tendo em vista tais questões, pretende-se, neste ensaio, verificar como a escrita de Ocampo reconfigura alguns elementos do gênero gótico. Para tanto, este trabalho apropria-se do referencial teórico sobre o fantástico na literatura e a literatura gótica de autoria feminina, em especial as discussões levantadas por Ellen Ledoux (2017), Ellen Moers (1976), Jaime Alazraki (2001), Sarolta Marinovich (1994), Tzvetan Todorov (2014), dentre outros nomes. Com base nesse arcabouço teórico, será realizada a leitura de alguns contos da escritora argentina, com o intuito de identificar e analisar a presença de marcas do gótico em sua obra.
\end{abstract} Ocampo

PALAVRAS-CHAVE: gótico feminino; crítica feminista; Literatura argentina; Silvina

ABSTRACT: Argentine writer Silvina Ocampo developed an instigating and consistent literary work, with special emphasis on her seven volumes of short stories, in which there is a remarkable presence of the fantastic. However, in addition to these characteristics, some features of the Gothic narrative can be seen throughout his work. In view of such questions, this essay aims to verify how Ocampo's writing reconfigures some elements of the Gothic genre. To this end, this work appropriates the theoretical framework on the fantastic in literature and the Gothic literature of female authorship, especially the discussions raised by Ellen Ledoux (2017), Ellen Moers (1976), Jaime Alazraki (2001), Sarolta Marinovich (1994), Tzvetan Todorov (2014), among others. Based on this theoretical framework, some stories by the Argentine writer will be read, in order to identify and analyze the presence of gothic marks in her work.

KEYWORDS: female Gothic; feminist criticism; Argentinean literature; Silvina Ocampo

\footnotetext{
${ }^{1}$ Doutor em Letras pela UFRGS. Professor-pesquisador no PPG em Letras da Universidade de Santa Cruz do Sul (UNISC).
} 


\section{Introdução}

Ao longo de mais de cinco décadas dedicadas à literatura, Silvina Inocencia Ocampo Aguirre publicou sete coletâneas de contos - Viaje olvidado, de 1937; Autobiografía de Irene, de 1948; La furia, de 1959; Las invitadas, de 1961; Los días de la noche, de 1970; Y así sucesivamente, de 1987; e Cornelia frente al espejo, de 1988 -, além de outras tantas narrativas, reunidas em livro postumamente. Na quase totalidade desses textos ficcionais, é recorrente a temática da experiência feminina, a partir de uma perspectiva que, na maior parte dos casos, subverte e problematiza as ideias e os comportamentos que sustentam a cultura patriarcal e o imaginário androcêntrico. Paralelamente, outra característica marcante da escrita da autora argentina é a presença do fantástico, do onírico e da ambiguidade em suas tramas. Tais elementos engendram uma estruturação narrativa paradoxal e desconcertante, na qual os atos de violência, muitas vezes praticados por personagens infantis ou que não têm consciência dos efeitos de suas ações, são descritos de forma quase ingênua.

Tais aspectos, apontados de maneira recorrente pela fortuna crítica da escritora, são facilmente observáveis à primeira leitura de seus contos. Contudo, a forma como se consolidou essa concepção em torno de sua obra impõe limites para qualquer aproximação que não se enquadre estritamente em tais paradigmas, a despeito das distintas possibilidades de leitura autorizadas por seus contos. Tomando tais reflexões como ponto de partida, buscarei neste ensaio rastrear algumas marcas do gótico na obra de Silvina Ocampo, com o intuito de demonstrar de que maneira tais características, ao se articularem com estratégias narrativas caras à autora, atualizam e redimensionam os limites desse tradicional gênero literário. Para tanto, lançarei mão de algumas discussões acerca dos conceitos de literatura fantástica e literatura gótica, em especial as proposições teóricas apresentadas por Ellen Ledoux (2017), Ellen Moers (1976), Jaime Alazraki (2001), Sarolta Marinovich (1994) e Tzvetan Todorov (2014).

Como corpus de análise, selecionei as narrativas "Cielo de claraboyas", "Eladio Rada y la casa dormida" e "El retrato mal hecho", reunidas em Viaje olvidado, de 1937; "Carta bajo la cama", presente em Las invitadas, de 1961; e "Jardín de infierno", conto publicado em Cornelia frente al espejo, de 1988. Porém, antes de proceder à leitura aqui proposta, é de fundamental importância discutir a concepção de literatura gótica, em especial as características da narrativa gótica de autoria feminina, e as diferenças que tal estilo apresenta 
em relação ao fantástico, gênero ao qual a obra de Silvina Ocampo é constantemente associada.

\section{A narrativa gótica de autoria feminina: características e delimitações conceituais}

Muito embora as leituras críticas acerca da narrativa curta produzida por Silvina Ocampo ressaltem a presença marcante do fantástico e de aspectos a ele relacionados - tais como o onírico, o ambíguo, o duplo, dentre outros -, é possível observar, a partir de uma leitura mais atenta, que tais elementos muitas vezes articulam-se com traços que remetem ao gótico. Tal convergência talvez decorra do fato de que esses dois conceitos estejam tão intimamente relacionados que, por vezes, torna-se difícil separá-los de forma tão clara. No entanto, a despeito de ambas problematizarem as premissas da narrativa realista, é sabido que essas duas concepções - o fantástico e o gótico - apresentam distinções bem claras entre si. Em sua clássica definição do termo, Tzvetan Todorov (2014[1970], p. 31) afirma que "o fantástico é a hesitação experimentada por um ser que só conhece as leis naturais, face a um acontecimento aparentemente sobrenatural”. Para o teórico búlgaro, o caráter de incerteza, para o personagem e principalmente para o leitor, é condição sine qua non para a emergência do fantástico. Nesse sentido, uma vez que se lance mão de explicações para compreender o que se passa na trama, seja com base em leis da natureza ou no sobrenatural, abandonamos a esfera do fantástico para adentrarmos no âmbito do estranho, no primeiro caso, ou do maravilhoso, no segundo.

Apesar de seu esforço para estabelecer os limites que encerram as características desse gênero da forma mais clara possível, o próprio Todorov reconhece as interfaces que o fantástico estabelece com o gótico. Nesse sentido, muito embora cite a obra de uma reconhecida autora da literatura gótica, tal como Ann Radcliffe, como exemplo de narrativa em que a incerteza do sobrenatural se manifesta por um momento, antes de ser solapada por uma explicação racional - o que ele denomina "fantástico-estranho" -, Todorov discorda categoricamente do argumento de H. P. Lovecraft de que o sentimento de medo, elemento reiteradamente relacionado ao gótico, constitui o aspecto definidor da literatura fantástica. $\mathrm{Na}$ mesma direção vai a reflexão do teórico argentino Jaime Alazraki (2001) que, ao propor o conceito de neofantástico, aponta com uma das diferenças centrais entre as produções contemporâneas deste gênero e as narrativas fantásticas do século XIX justamente o fato de que aquelas não apresentam, como intenção primordial, provocar o medo em quem lê. 
Sobrepondo-se às similaridades, o sentimento do medo claramente se impõe como o marco que distingue o fantástico do gótico. Como define Ellen Moers (1976, p. 90), “[i]n Gothic writings fantasy predominates over reality, the strange over the commonplace, and the supernatural over the natural, with one definite auctorial intent: to scare". Paralelamente a isso, a literatura gótica encontra, na simbolização do espaço em que se desenrola a trama, outro de seus aspectos definidores. Nesse sentido, em sua origem, tal gênero literário consolidou no imaginário ocidental um vínculo muito forte entre essas narrativas e espaços bem delineados e com características bastante marcantes, como castelos ou casarões aterrorizantes, labirínticos e com cômodos enigmáticos e proibidos, nos quais, geralmente, personagens femininas encontram-se aprisionadas e subjugadas à opressão de um personagem masculino.

Em sua reflexão acerca do gótico feminino, a teórica estadunidense lança as bases para uma discussão acerca dos matizes decorrentes do gênero da autoria dos textos góticos. Segundo ela, um dos aspectos que se constitui como principal elemento de distanciamento entre o gótico masculino e o feminino é a relação que as mulheres estabelecem com seu corpo, em especial no que tange às questões relativas à gestação e à maternidade. Em sua análise do gótico feminino, Moers chama a atenção para o fato de que, muito embora não apresente personagens femininas como protagonistas, o romance Frankenstein, tido como um dos textos fundadores do que se poderia chamar de uma tradição da literatura gótica de autoria feminina, pode ser lido como uma narrativa que discute a ansiedade, o trauma e o medo envolvidos no processo de maternidade. Nesse sentido, Mary Shelley "brought birth to fiction not as realism but as Gothic fantasy, and thus contributed to Romanticism a myth of genuine originality: the mad scientist who locks himself in his laboratory and secretly, guiltily works at creating human life, only to find that he has made a monster" (MOERS, 1976, p. 93). Na esteira desse pensamento, Sarolta Marinovich (1994, p. 201) assinala que "[i]n the Gothic written by a man the fear and the threat is from someone else's body, in the Female Gothic the problem is 'internal', (...) the source of fear, guilt and disgust is her very own body".

Longe de ser o lócus de uma construção positiva da própria identidade, o corpo, na maioria das narrativas góticas de autoria feminina, configura um elemento de estranhamento, algo que causa inquietação, angústia, repulsa e que coloca em xeque algumas certezas a respeito da subjetividade feminina. Nas palavras de Marinovich (1994, p. 198) "[t]he Gothic fear is revealed as the fear of femaleness itself, perceived as threatening to one's wholeness, obliterating the very boundaries of the self". No mesmo sentido havia sido direcionada a 
reflexão de Ellen Moers, ao observar que a visão do corpo feminino como objeto de aversão e temor, algo recorrente no gótico feminino do século XX, pode ser compreendida como uma elaboração literária que problematiza a compulsão de olhar e avaliar o próprio corpo que marca a experiência do feminino na cultura patriarcal. Nesse contexto, o sentimento de inadequação às normas impostas pela sociedade com relação ao papel a ser desempenhado pela mulher - normas essas que não apenas controlam e alienam o corpo feminino, como também, a partir das expectativas impostas pelas ideias de casamento e maternidade, estabelecem uma relação de espelhamento entre o corpo da mulher e o da sua mãe - constitui um terreno bastante profícuo para a produção de narrativas góticas de autoria feminina. Assim sendo, partindo da premissa de Sarolta Marinovich (1994) de que a literatura gótica escrita por mulheres configura um "discurso do outro", constituindo um espaço de expressão da condição feminina de ser um "estranho" na sociedade masculina, é possível afirmar que a concepção do corpo como fonte de angústia e medo instaura uma leitura crítica e uma estratégia de subversão ao imaginário e às imposições socioculturais de tal contexto.

O protagonismo que o gótico feminino contemporâneo concede ao corpo como elemento aterrorizante assume, muitas vezes, a configuração de corporalidades monstruosas. Essa constatação, feita já por Ellen Moers em meados da década de 1970, de que as autoras do gótico povoam suas narrativas com "aberrações”, marcadas não apenas por deformidades hediondas, como também pela ambiguidade sexual, reverbera na leitura proposta por Sarolta Marinovich. Para a pensadora húngara, tal aspecto tem relação direta com a experiência de gênero, uma vez que "the protagonists of modem Female Gothic are compelled to confront a monstrous image of self as a grotesque body represented by images of pregnancy and procreation" (MARINOVICH, 1994, p. 195). Se, por um lado, o medo e a aversão ao próprio corpo denotam o olhar crítico que o gótico feminino lança sobre a identidade e a experiência femininas, por outro, uma vez que esse sentimento de angústia provém de uma concepção cultural que naturaliza o corpo feminino como lócus da reprodução, tomando o casamento e a maternidade como papéis essenciais e definidores da condição feminina, essa corporalidade abjeta e estranha às protagonistas femininas assume o caráter de prisão. Em suas considerações acerca do gótico feminino contemporâneo, Marinovich (1994, p. 195) propõe uma aproximação entre espaço e corpo, uma vez que "[t]he heroine's exploration of her entrapment in a Gothic house can be read as an exploration of the femaleness of experience". Similar é a concepção de Emma Domínguez-Rué, para quem o ambiente doméstico e a figura masculina são a base para a atmosfera gótica nas narrativas de autoria feminina. Segundo a 
autora, nessas obras "the house is an imprisoning, almost suffocating setting within which the female protagonist is trapped, while the threatening male hides a secret which most of the time surrounds a supernatural figure or event.” (DOMÍNGUEZ-RUÉ, 2014, p.126).

Tendo em vista o exposto até aqui, parece-me bastante explícita a complexa articulação entre os elementos do corpo e do espaço que a literatura gótica produzida por mulheres coloca em funcionamento. Do ponto de vista da cultura patriarcal, esse dois elementos são vistos como definidores da condição feminina, a partir do jogo binário e reducionista que relaciona o feminino ao biológico natural e ao espaço doméstico, ao passo que o masculino está atrelado ao espírito e à razão, bem como ao espaço público e político. Ao inter-relacionar tão intimamente essas duas ideias na imagem do corpo como espaço que aprisiona, a narrativa gótica problematiza a "familiaridade" que a mulher pretensamente teria com ambos os elementos, dando a eles o caráter de Unheimliche, do qual fala Freud (1976[1919]). Nesse contexto, longe de configurar o espaço da segurança e do acolhimento, como propõe Gaston Bachelard (2008[1957]), a casa torna-se um espaço vinculado a sentimentos como medo, angústia e horror, muitas vezes por representar o palco de violências físicas e psicológicas.

Porém, a despeito de todos os esforços em delimitar e caracterizar a produção literária de autoria feminina dentro dessa temática, o conceito de "gótico feminino" está longe de ser um consenso no âmbito da crítica feminista. Estudiosas como Ellen Ledoux, por exemplo, compreendem que o uso de tal categoria acaba por trazer mais problemas do que soluções em termos de abordagem e interpretação de algumas obras escritas por mulheres. Em seu ensaio sugestivamente intitulado "Was there ever a 'Female Gothic'?", a autora aponta que "women authors' relationship to the burgeoning Gothic mode was richer and more nuanced than previously thought in ways that demand that we widen the lens with which we approach women's Gothic productions from the eighteenth century to the present" (LEDOUX, 2017, p. 02). Nesse sentido, narrativas de autoria feminina que não apresentam o conjunto de aspectos que definem o gótico feminino - protagonismo de uma personagem feminina angustiada, encarceramento doméstico, ameaças de violência sexual, sentimentos de ansiedade, figuras maternas monstruosas ou ausentes - acabam não recebendo a devida atenção por não se enquadrarem em uma delimitação de gênero, em certo sentido, bastante excludente e que não reflete plenamente a riqueza e a diversidade da narrativa gótica produzida por mulheres. Sem desviar muito dessa linha de raciocínio, Sarolta Marinovich, retomando a concepção de Ellen Moers, enfatiza que o gótico refere-se a um modo de escrita, e não apenas a um gênero 
literário. Contudo, diferentemente da sua colega estadunidense, a teórica feminista húngara entende o conceito de forma mais ampla, desvinculando-o de aspectos espaciais, como ruínas assombradas ou paisagens sombrias, muito embora, conforme visto anteriormente, o espaço não seja, de modo algum, totalmente descartado do conceito de gótico operado por Marinovich.

\section{Os elementos góticos na narrativa de Silvina Ocampo: apropriação e subversão}

Não tão conhecida do grande público quanto as personalidades que compunham seu círculo de relações mais íntimo - como seu esposo, Adolfo Bioy Casares, sua irmã mais velha, Victoria Ocampo, e seu amigo Jorge Luis Borges -, a argentina Silvina Ocampo é autora de uma vasta, diversificada e instigante produção literária, que reúne narrativas curtas e longas, poesia, peças teatrais e obras para o público infantil. Sua ficção, em especial os contos, tem sido interpretada com frequência pela crítica literária a partir de uma chave de leitura que a enquadra nos estreitos limites do insólito, do fantástico e do onírico. Apesar de não se poder negar que sua escrita lança mão reiteradamente de tais artifícios de subversão da representação mimética, reduzi-la a esses termos faz com que se perca de vista muitas outras possibilidades interpretativas a que seus textos estão abertos. Partindo dessa permissa, tentarei aqui, conforme já dito, apresentar a relação que a narrativa de Silvina Ocampo por vezes estabelece com a literatura gótica, em um diálogo que ora retoma, ora subverte os elementos definidores desse estilo.

Muito embora seja possível identificar, com maior ou menor nitidez, essa interface com o gótico em diversos momentos da obra da autora argentina, selecionei um conjunto de cinco contos como corpus para o estudo que proponho aqui. São eles: "Cielo de claraboyas", "Eladio Rada y la casa dormida" e "El retrato mal hecho", publicados em Viaje olvidado, de 1937; "Carta bajo la cama", uma das narrativas de Las invitadas, de 1961; e "Jardín de infierno", publicado em Cornelia frente al espejo, de 1988. A partir da leitura dessas narrativas, pretendo apontar e discutir o uso que a escritora faz de algumas características relacionadas ao gótico, buscando argumentar que a presença de tais elementos, a princípio não considerada como algo recorrente em sua obra, pode ser vista como um elemento de subversão instaurado pela escrita de Silvina Ocampo, uma vez que desestabiliza a tentativa de compreendê-la a partir de categorias que se mostram incapazes de conter sua proposta estética. Dito de outra forma, se concordamos com Ellen Ledoux e reconhecemos os limites 
do conceito de gótico para compreender a produção de autoras que não se encaixam nas limitações demasiado estritas de tal categoria, podemos, na mão inversa, ponderar que a chave de leitura do insólito e do fantástico se mostra igualmente insuficiente para abarcar as distintas possibilidades interpretativas oferecidas pela narrativa de Silvina Ocampo.

Tomo, como eixos condutores desta análise, os elementos do espaço gótico, simbolizado como um ambiente labiríntico, enigmático, mas também opressor e aterrorizante, e da violência psíquica e física, ações que, geralmente, configuram o cerne da trama das narrativas góticas. Quando se aborda a questão da ambientação na obra de Silvina Ocampo, observa-se que, em algumas de suas narrativas, a autora lança mão de uma elaboração do espaço da trama que reproduz claramente os elementos da literatura gótica, quais sejam, lugares ermos, aterrorizantes e opressivos. É o caso dos contos "Jardín de infierno" e "Carta bajo la cama". A primeira narrativa, que integra o livro Cornelia frente al espejo, lançada em 1988, talvez seja aquela que, de forma mais explícita, é construída a partir dos elementos espaciais mais característicos do gótico. Já no parágrafo inicial do texto, o personagemnarrador do conto apresenta o inusitado local em que se passa a trama: "Este enorme castillo solitario me asusta y se llena, cuando me quedo solo, de ruidos. Las angostas y altas ventanas dejan entrar un poco de luz sobre mis libros de estudio.” (OCAMPO, 2007b, p. 315). Essa ambientação misteriosa e fantasmagórica é reforçada mais adiante, quando o personagem começa a observar algo que lhe intriga:

\footnotetext{
En un lugar del castillo, que parecía siempre tan desierto, había un cuarto cerrado con llave, llave que estaba en el llavero consuetudinario. El hecho de que ese único cuarto estuviera cerrado empezó a preocuparle gravemente. De noche salía al jardín a pesar de los perros feroces, que ladraban por la insólita hora en que salía. Examinó una por una las persianas para ver si había luz. Le pareció ver un resplandor en una de ellas. (OCAMPO, 2007b, p. 316)
}

Não se distanciando muito em termos de construção do espaço narrativo, o conto "Carta bajo la cama", publicado no livro Las invitadas, de 1961, transcorre em uma casa isolada no sul da Inglaterra, na qual o silêncio, a escuridão e a solidão marcam o cenário da narrativa e intensificam o clima de tensão. Próximo à casa, um pequeno bosque, no qual a protagonista se refugia com frequência, contribui para a ambientação na qual o medo, tido incialmente como um motivo de distração, intensifica-se até tornar-se um sentimento insuportável. Diferentemente do bosque, local em que a personagem sente-se confortável por estar sozinha, a casa que habita não possibilita a reclusão absoluta, seja pelo fato de a ausência de cortinas nas janelas de vidro deixar exposto o que ocorre no interior da habitação, 
seja pelo fato de que todas as pessoas do povoado próximo têm acesso à chave da porta principal, algo que não é visto por ela como motivo de preocupação:

Es claro que el sitio es tranquilo y la gente tan buena, que al salir ponemos la llave sobre el soporte del farol de entrada, de modo que el almacenero, el lechero o el cartero puedan dejar paquetes o cartas adentro de la casa. Todo el pueblo sabe dónde está la llave de la puerta de entrada. (OCAMPO, 2007a, p. 326)

Se, por um lado, a narrativa de Silvina claramente retoma o isolamento do espaço como uma das marcas da literatura gótica, por outro, ela também opera o que se poderia chamar de uma "atualização" dessa ambientação, reproduzindo-a tanto em residências localizadas em centros urbanos - como se verifica em "Cielo de claraboyas", conto publicado em Viaje olvidado, de 1937, que se passa no apartamento da tia mais velha da menina narradora - quanto em habitações que se encontram no espaço rural, como no conto "Eladio Rada y la casa dormida", também publicado em Viaje olvidado, cuja trama se passa na sede de uma fazenda.

No que tange à visão do espaço como a fonte do medo e da angústia vivenciados por quem o habita, é possível observar que muitos dos ambientes das narrativas de Silvina Ocampo recém-mencionadas configuram-se como locais que oprimem, de forma muitas vezes extremamente violenta, as personagens femininas. A retomada desse elemento gótico clássico é verificada, sobretudo, em contos como "Carta bajo la cama", "Cielo de claraboyas" e "El retrato mal hecho". Em "Carta bajo la cama", muito embora a solidão e o isolamento tragam no princípio sentimentos de tranquilidade e serenidade à protagonista, com o desenrolar da trama, esses sentimentos positivos vão dando lugar a um medo e a uma apreensão crescentes. Assim, a casa, próxima a um vilarejo no sul da Inglaterra, que inicialmente tinha algo de familiar, fazendo-lhe, por vezes, recordar sua terra, começa gradativamente a ser o palco de acontecimentos estranhos e assustadores.

\footnotetext{
Desde hace unos instantes oigo un ruido, un ruido que me trae algún recuerdo de infancia, el ruido que hace una rala (hermana del rastrillo) en la tierra húmeda. ¿Pero quién puede trabajar a estas horas? ¿Una pala invisible? Si pienso un poco puedo asustarme. ¿Prefiero que esa pala que golpea rítmicamente la tierra sea invisible? Involuntariamente, de un misterio elijo la versión que más me asusta. Me vuelvo hacia el este donde está el otro ventanal, que no tiene mayor atractivo. Hay una bolsa en el suelo. La bolsa se mueve: es un hombre arrodillado. Está cavando la tierra. (OCAMPO, 2007a, p. 327)
}

O lugar, a princípio silencioso e vazio, passa a ser invadido por sons de rastilho e a contar com a presença de um estranho a trabalhar no jardim. O surgimento desse homem misterioso torna-se algo apavorante quando a mulher toma conhecimento, no noticiário da 
tevê, dos crimes cometidos por um assassino em série que, sob o disfarce de jardineiro e na companhia de duas cúmplices, mata e esquarteja mulheres, utilizando seus corpos como adubo para plantas. A imediata associação entre o criminoso e a figura que ela vê pela janela faz com que a protagonista fique petrificada de pavor:

Desconecto el televisor. El ruido de la pala continúa. No puedo casi moverme. Estoy paralizada. El hoyo se agranda; es un agujero negro. Junto al agujero vislumbro una planta tirada en el suelo. ¿Dónde podré esconderme? Estoy en una casa de vidrio, y el hombre me mira continuamente. (OCAMPO, 2007a, p. 328)

O desfecho enigmático do conto, que indica claramente que a mulher foi assassinada, não deixa dúvidas quanto à possibilidade de compreender a trama pelas lentes do gótico. Contudo, se levarmos em consideração que o assassinato foi praticado por pessoas que não apresentam nenhuma relação com a casa que provoca os sentimentos de angústia e pavor na mulher que nela habita, é possível afirmar que a narrativa de Silvina Ocampo rompe com a tendência, apontada pelas estudiosas do gótico feminino, de relacionar o medo com aspectos internos das personagens femininas, mais especificamente com a relação que essas estabelecem com seu corpo, visto como materialização da sua feminidade. Nesse sentido, se concordamos com a já referida afirmação de Sarolta Marinovich de que, no gótico de autoria feminina, a origem do horror é interna e corresponde a um "medo da feminilidade", o que se observa aqui é que, mesmo sem se enquadrar nesse quesito, a escrita da autora argentina sustenta um nítido vínculo com o estilo gótico, tomado aqui em sua concepção mais ampla proposta por Ellen Ledoux, já discutida neste ensaio.

$\mathrm{Na}$ mesma linha vão as considerações que podem ser feitas acerca de "Cielo de claraboyas". Publicada mais de vinte anos antes, essa narrativa também retoma, de forma bastante explícita, os elementos do gótico, em especial a ambientação fantasmagórica. A trama, narrada por uma menina que visita a casa da tia, relata os misteriosos acontecimentos que sucedem com uma família composta por duas mulheres, um homem e uma criança, que habita os cômodos da parte superior. Diferentemente da narrativa de "Carta bajo la cama", o que se passa na residência dessa família não é visto com tanta nitidez, fato que resulta em imagens grotescas e assustadoras construídas pela imaginação da pequena narradora.

Encima del hall de esa casa con cielo de claraboyas había otra casa misteriosa en donde se veía vivir a través de los vidrios una familia de pies aureolados como santos. Leves sombras subían sobre el resto de los cuerpos dueños de aquellos pies, sombras achatadas como las manos vistas a través del agua de un baño.

(...)

No había nadie ese día en la casa de arriba, salvo el llanto pequeño de una chica (a quien acababan de darle un beso para que se durmiera,) que no quería dormirse, y la 
sombra de una pollera disfrazada de tía, como un diablo negro con los pies embotinados de institutriz perversa. Una voz de cejas fruncidas y de pelo de alambre que gritaba "¡Celestina, Celestina!", haciendo de aquel nombre un abismo muy oscuro. (OCAMPO, 2007a, p. 11)

Além do aspecto visual das personagens, a referência aos elementos religiosos - "pés aureolados", "diabo negro", "Celestina" - pode também ser apontada como um traço gótico. Contudo, o que parece constituir o principal ponto de convergência entre a escrita de Ocampo e tal estilo literário é a ocorrência de um infanticídio e a forma como ele é narrado.

(...) Y de nuevo surgió una risa de pelo suelto, y la voz negra gritó, haciendo un pozo oscuro sobre el suelo: "¡Voy a matarte!". Y como un trueno que rompe un vidrio, se oyó el ruido de jarra de loza que se cae al suelo, volcando todo su contenido, derramándose densamente, lentamente, en silencio, un silencio profundo, como el que precede al llanto de un chico golpeado.

Despacito fue dibujándose en el vidrio una cabeza partida en dos, una cabeza donde florecían rulos de sangre atados con moños. La mancha se agrandaba. De una rotura del vidrio empezaron a caer anchas y espesas gotas petrificadas como soldaditos de lluvia sobre las baldosas del patio. (...)

La pollera volvió a volar en torno de la cabeza muerta: "¡Celestina, Celestina!", y un fierro golpeaba con ritmo de saltar a la cuerda.

Las puertas se abrían con largos quejidos y todos los pies que entraron se transformaron en rodillas. La claraboya era de ese verde de los frascos de colonia en donde nadaban las faldas abrazadas. Ya no se veía ningún pie y la pollera negra se había vuelto santa, más arrodillada que ninguna sobre el vidrio. (OCAMPO, 2007a, p. 12)

Seja pelo fato de a morte de Celestina ter ocorrido no espaço familiar, seja em função de esse espaço adquirir, aos olhos da narradora, uma áurea de mistério, de enigma e, pode-se dizer, de horror, ou ainda pelo impacto que a cena causou na criança que a presenciou, impacto esse reproduzido nas escolhas lexicais da narradora - os gritos de uma voz negra, um poço escuro aberto no chão, grandes e grossas gotas de sangue petrificadas, a saia negra voando sobre a cabeça da criança, os longos gemidos das portas se abrindo -, os quais denotam a carga pesada e sombria do episódio, o trecho supracitado apresenta similaridades, acredito que inquestionáveis, com a linguagem e as imagens que caracterizam a literatura gótica.

Diferentemente do que se afirmou sobre os contos discutidos até aqui, "El retrato mal hecho" é a narrativa que mais claramente retoma um traço tido como emblemático da literatura gótica de autoria feminina, qual seja, a problematização do enaltecimento da maternidade. Em uma trama que gira em torno de duas figuras femininas centrais - Ana, a criada da casa, e Eponina, a patroa -, a voz narrativa nos apresenta o cotidiano em que os papéis de mãe e esposa são encenados a contragosto. 
A los chicos les debía de gustar sentarse sobre las amplias faldas de Eponina porque tenía vestidos como sillones de brazos redondos. Pero Eponina, encerrada en las aguas negras de su vestido de moiré, era lejana y misteriosa; (...)

Detestaba los chicos, había detestado a sus hijos uno por uno a medida que iban naciendo, como ladrones de su adolescencia que nadie lleva presos, a no ser los brazos que los hacen dormir. Los brazos de Ana, la sirvienta, eran como cunas para sus hijos traviesos.

La vida era un larguísimo cansancio de descansar demasiado; la vida era muchas señoras que conversan sin oírse en las salas de las casas donde de tarde en tarde se espera una fiesta como un alivio. Y así, a fuerza de vivir en postura de retrato mal hecho, la impaciencia de Eponina se volvió paciente y comprimida, e idéntica a las rosas de papel que crecen debajo de los fanales. (OCAMPO, 2007a, p. 32)

Se é bem verdade que Eponina encontra-se presa a uma condição doméstica que lhe é imposta mas à qual acaba se sujeitando, Ana, por sua vez, está submetida a uma condição de trabalho que a exaure, assumindo inclusive o cuidado dos filhos que sua patroa rejeita.

La mucama la distraía con sus cantos por la mañana, cuando arreglaba los dormitorios. Ana tenía los ojos estirados y dormidos sobre un cuerpo muy despierto, y mantenía una inmovilidad extática de rueditas dentro de su actividad. Era incansablemente la primera que se levantaba y la última que se acostaba. Era ella quien repartía por toda la casa los desayunos y la ropa limpia, la que distribuía las compotas, la que hacía y deshacía las camas, la que servía la mesa. (OCAMPO, 2007a, p. 32)

Da mesma forma que Eponina busca esconder sua não adequação ao papel de esposa e mãe, valendo-se para tanto da alienação e do distanciamento em relação às questões do lar, Ana também disfarça o fardo do trabalho doméstico que executa. Mesmo que a temática da opressão do ambiente doméstico possa ser vista, por si só, como um ponto de contato entre a narrativa de Ocampo e as características definidoras do gótico feminino, tal aproximação acaba por não tornar-se tão nítida, uma vez que é, em certa medida, ocultada pelo véu de aparente tranquilidade sugerida pelas atitudes das duas personagens. Contudo, o sofrimento a que Ana é submetida não é suportado em silêncio por muito tempo, e é justamente seu ato violento de afronta à situação que instaura, da maneira mais explícita possível, a violência gótica no conto.

(...) Ana no llegaba para servir la mesa; toda la familia, compuesta de tías, maridos, primas en abundancia, la buscaba por todos los rincones de la casa. No quedaba más que el altillo por explorar. Eponina dejó el periódico sobre la mesa, no sabía lo que quería decir albaricoque: "Las venas y los tallos color albaricoque". Subió al altillo y empujó la puerta hasta que cayó el mueble que la atrancaba. Un vuelo de murciélagos ciegos envolvía el techo roto. Entre un amontonamiento de sillas desvencijadas y palanganas viejas, Ana estaba con la cintura suelta de náufraga, sentada sobre el baúl; su delantal, siempre limpio, ahora estaba manchado de sangre. Eponina le tomó la mano, la levantó. Ana, indicando el baúl, contestó al silencio: "Lo he matado".

Eponina abrió el baúl y vio a su hijo muerto, al que más había ambicionado subir sobre sus faldas: ahora estaba dormido sobre el pecho de uno de sus vestidos más viejos, en busca de su corazón. 
(...)

Eponina se abrazó largamente a Ana con un gesto inusitado de ternura. (...) (OCAMPO, 2007a, p. 33)

Somando-se à óbvia referência provocada pela ideia do sótão em estado de decadência como palco do infanticídio cometido por Ana, o desfecho dessa narrativa apresenta um segundo ponto de contato com o gótico feminino, este relacionado à questão da maternidade. Contudo, mais do que apenas retomar uma marca do referido estilo literário, Silvina Ocampo se apropria dele, articulando-o com aspectos muito caros à sua linguagem. Em outras palavras, parece-me bastante plausível afirmar que o conto revela um elemento recorrente na produção literária da escritora argentina - o duplo -, aqui simbolizado não apenas na atitude "maternal" de Ana, que fazia os filhos de Eponina dormirem em seus braços, como também na cumplicidade entre ambas, demonstrada pelo abraço que a patroa dá na criada. Na esteira desse raciocínio, a sobreposição da ideia do duplo associa a esse ato violento uma crueldade ainda maior e, por extensão, intensifica ainda mais seu vínculo com o gótico, uma vez que, metaforicamente, a morte da criança pode ser vista, em certa medida, como uma espécie de filicídio.

Não obstante o fato de as narrativas discutidas até aqui serem protagonizadas por personagens femininas, observa-se que, por vezes, Silvina Ocampo retoma alguns aspectos do gótico direcionando a personagens masculinas a angústia e o medo próprios do estilo. É o caso do já citado "Jardín de infierno", no qual, muito embora a ambientação seja o mais fidedigna possível aos ditames desse gênero literário, é um homem que se encontra aprisionado a uma relação matrimonial infeliz, metaforizada no enorme, solitário e assustador castelo que habita. Durante os momentos em que sua esposa não está no castelo, a curiosidade do homem sobre os casamentos anteriores dela e, principalmente, sobre o que se encontra por trás da porta de um cômodo que lhe foi expressamente proibido abrir gera uma angústia crescente, perturbadora, insuportável. Um dia, aproveitando que a esposa não se encontra no castelo e ignorando a confiança depositada por ela, o homem decide entrar no misterioso quarto e lá se depara com os cadáveres de seis homens pendurados. Ao regressar no final do dia, a mulher procura pelo esposo e, ao ingressar na peça em que ele não deveria entrar, depara-se com um bilhete suicida informando que seu corpo encontra-se pendurado junto aos dos seus outros falecidos maridos.

À semelhança do que ocorre nos demais contos que constituem o corpus desta análise, também a trama de "Eladio Rada y la casa dormida" transcorre em uma habitação de grandes proporções, vazia, decadente e assustadora. 
La casa era de varios pisos. (...) En los techos crecían cada día nuevas telarañas que enardecían el plumero más alto de la casa; y brotaba de los muebles y de las sábanas guardadas como plantas de un invernáculo obscuro, olor a choclo recién cortado.

(...)

Había lugares inexplorados de la casa, en donde se oían ruidos, de noche, que lo despertaban; entonces se levantaba con la escopeta que le habían dado los patrones, revisaba las persianas, pero nunca llegaba hasta ese lugar lejano y misterioso por donde entran los ruidos de la noche que hacen ladrar a los perros. (OCAMPO, 2007a, p. 26)

Nesse espaço isolado, o personagem que dá título ao conto vive os meses de inverno tendo por companhia apenas os cães que o ajudam a proteger a propriedade rural da qual é caseiro. Assim como em "Jardín de infierno", aqui também a questão central da história refere-se à relação de uma figura masculina com o matrimônio e a vida conjugal, porém, diferentemente do conto de 1988, em "Eladio Rada y la casa dormida" o que causa a angústia é o casamento não concretizado:

En esos momentos en que la cabeza de Eladio se surcaba de corredores por donde paseaba Angelina, su novia perdida, invariablemente oía ruidos de ladrones invisibles que hacían ladrar los perros, y salía por la casa desierta a revisar las persianas que se multiplicaban alrededor de la casa. (OCAMPO, 2007a, p. 27)

Tomadas em paralelo, essas duas narrativas exemplificam, cada uma a seu modo, o processo de redimensionamento do gótico que pode ser apontado na escrita de Silvina Ocampo, uma vez que nelas os elementos opressivos e aterrorizantes, que em geral configuram a ambientação gótica, não apenas recaem sobre personagens masculinos, mas operam em uma esfera tradicionalmente vinculada pela sociedade patriarcal à figura feminina, qual seja, o casamento.

\section{Considerações finais}

Embora sejam lidos, de forma quase que exclusiva, a partir das lentes do fantástico, os contos de Silvina Ocampo possibilitam uma interpretação muito mais ampla, apresentando, dentre outros aspectos, diversos elementos temáticos e de linguagem que os relacionam à literatura gótica. Como procurei demonstrar aqui, a partir da discussão de algumas dessas narrativas, as características desse gênero não apenas são apropriadas pela escritora argentina, como também redimensionadas em sua obra. Assim, é possível observar que as ideias de isolamento, fantasmagoria e pavor, intimamente relacionadas, no gótico tradicional, a espaços ermos e decadentes, acabam por ser, em alguns textos de Ocampo, deslocadas para espaços urbanos. 
Somado a isso, nota-se igualmente que um traço marcante da narrativa gótica de autoria feminina - a opressão e a angústia sofridas por personagens femininas -, muito embora possa ser observado na obra da contista, acaba, em larga medida, sendo subvertido, uma vez que tais sentimentos raramente se relacionam à questão do corpo, da maternidade e do casamento. Nesse sentido, configurando mais um indício do redimensionamento que Ocampo propõe a esse gênero literário, verifica-se que o tema do matrimônio, tido, de forma geral, como ponto desencadeador da violência física e/ou emocional sofrida pelas personagens femininas dessas narrativas, constitui, na ficção da autora argentina, a fonte de sentimentos negativos, muitas vezes, experimentados pelos personagens masculinos.

Obviamente, o propósito da leitura aqui empreendida não foi esgotar as possibilidades de associação entre os contos de Silvina Ocampo e o gênero gótico. No entanto, mesmo que bastante sucinto, o mapeamento apresentado parece-me não deixar dúvidas quanto ao caráter instigante e problematizador da escrita da autora, a qual reiteradamente rompe com certezas arraigadas e cristalizadas em nosso imaginário, inclusive aquelas com que buscamos domesticar a sua obra.

\section{REFERÊNCIAS}

ALAZRAKI, Jaime. ¿Qué es lo neofantástico? In: ROAS, David (org.). Teorías de lo fantástico. Madrid : Arco/Libros, 2001, p. 265-282.

BACHELARD, Gaston. A poética do espaço. Tradução de Antonio de Pádua Danesi. 2 ed. São Paulo: Martins Fontes, 2008.

DOMÍNGUEZ-RUÉ, Emma. Nightmares of repetition, dreams of affiliation: female bonding in the Gothic tradition. Journal of Gender Studies, Vol. 23, No. 2, 125-136, 2014.

FREUD, Sigmund. "O Estranho". In: ESB. Volume XVII. Rio de Janeiro: Imago, 1976, p. 271-318.

LEDOUX, Ellen. "Was There Ever a 'Female Gothic'?” Palgrave Communications, vol. 3, 2017, p. 1-7.

MARINOVICH, Sarolta. The discourse of the Other: female Gothic in contemporary women's Writing. Neohelicon. East Lansing, v. 21, n. 1, p. 189-205, 1994.

MOERS, Ellen. Literary women. Doubleday \& Company, INC., Garden City, New York, 1976.

OCAMPO, Silvina. Cuentos completos I. 2. ed. Buenos Aires: Emecé Editores, 2007. 
OCAMPO, Silvina. Cuentos completos II. 2. ed. Buenos Aires: Emecé Editores, 2007.

TODOROV, Tzvetan. Introdução à literatura fantástica. Tradução de Maria Clara Correa Castello. 4. ed. São Paulo: Perspectiva, 2014.

Recebido em 30/8/2020.

Aceito em 20/01/2021. 